\title{
The Books That Lived: J.K. Rowling and the Magic of Storytelling
}

\begin{abstract}
This essay addresses the question of "what makes a bestseller?" It seeks to come to a better understanding of the various factors that contribute significantly to the outstanding popular appeal and commercial success of bestsellers, using J.K. Rowling's fiction as a case study. The reception of her work in quality media allows an exploration of Rowling's phenomenal success with the Harry Potter series, and invites a comparison with the success of her next two novels, The Casual Vacancy (2012) and The Cuckoo's Calling (2013), both written for adult readers. The context that the essay draws on is provided by literary theories about bestsellers and their features, rather than the commercial/marketing context of the bestseller. Also commenting on the influence of reviews on bestselling success, and the contested literary status of bestsellers, the essay hopes to shed some light on what constitutes "the magic of storytelling" in bestseller success.
\end{abstract}

\section{Key words}

Bestseller debates; reviewing; literary success; the Potter phenomenon

"As the novel's cultural centrality dims, so storytelling - J.K. Rowling's magical Owl of Minerva, equipped for a thousand tricks and turns - flies up and fills the air."

James Wood

It needs no explanation that Wood's reference is this essay's epigraph is to the seven-volume series of Harry Potter, the long narrative of the life and times of the Boy Who Lived. With half a billion books sold worldwide, and translated into over seventy languages, the Potter phenomenon contradicts the current sense that we are witnessing the disappearance of the book. Claims about the death of 
the novel, "a critical commonplace since the mid-twentieth century" (Dawson 2013: 5), point at competition from new media, online publishing and digital technologies. However, public interest in bestselling novels remains unabated; major literary prizes continue to attract media attention and guarantee bestselling success to literary novels. The bestseller lists contradict the "perceived decline in the cultural authority of the novel" (Dawson 2013: 5).

What are the qualities that make bestselling novels stand out from the multitude of published books, and effectively contradict the death of the novel? What is the influence of reviews in creating bestselling success? Are bestsellers by definition of inferior literary quality, and can it be asserted that they lack cultural authority? If there is such a thing as the magic of storytelling, how can it be measured? In this essay we address these questions using J.K. Rowling's Harry Potter as a case study, the children's book series that became a phenomenon. While Harry Potter brings us the mysterious magic of storytelling, a phrase often used by reviewers, we may wonder whether this magic is also to be found in Rowling's next novels, The Casual Vacancy (2012) and The Cuckoo's Calling (2013), both written for adult readers. ${ }^{1}$ Flying on the wing of Rowling's fame, The Casual Vacancy sold 125,000 copies in its first week, "the second-biggest adult opening of all time in the United Kingdom, falling short only of Dan Brown's 2009 novel, The Lost Symbol" (Farr 2012). The release of Rowling's next book, a detective novel titled The Cuckoo's Calling, was far less spectacular because the novel debuted under the pseudonym of Robert Galbraith. During the three months of Galbraith's authorship the book did not become a bestseller, but its sales sky-rocketed on the day Rowling's authorship was disclosed. Due to Rowling's use of a pseudonym, we can investigate the reviewers' reception of Calling prior to what is called the "brand-name effect," the effect of an author's established reputation as bestseller writer. The reception of Rowling's novels published between 1997 and 2013 affords insight into what reviewers, as professional readers, evaluate as outstanding in her work. While it is surely impossible to present a list of ingredients guaranteed to produce a bestseller, it is intriguing to find at least some answers to the question of what makes a bestseller, and what is meant by that mysterious phrase: the magic of storytelling.

\section{The making of a phenomenon}

It is one of the ironies of book publishing that Rowling's first book, Harry Potter and the Philosopher's Stone, was rejected by several publishers before Bloomsbury accepted it. It came out in June 1997 in London and reached the top of the prestigious New York Times Best Seller List in August 1999. The second and third books in the series, Harry Potter and the Chamber of Secrets and Harry Potter and the Prisoner of Azkaban were published in the next two years and by 2000 the three books had occupied the top three places of The New York Times Best Seller List in adult fiction for over a year (Bolonik 2000). This amazing success is not to be attributed to any feat of marketing: 
It was achieved and sustained entirely by personal recommendation, schoolyard conversations, Internet chat rooms, and sheer consumer satisfaction, enthusiasm, evangelism... call it what you will. The normal apparatus of pre-teen marketing - television programs, product placement, soda pop sponsorship deals, and so on-was conspicuous by its absence. (Brown 2002: 8)

The first marketing-driven release of the series was Harry Potter and the Goblet of Fire. The strategy was designed to shroud its appearance in mystery: there was no advance information, no review copies, no author interviews, and a deferral of foreign translations (Brown 2002: 12). The book's release on 8 July 2000 demonstrated what has become known as 'Pottermania': long lines of "pajamaclad, broomstick-clutching, wizards-cap-wearing" children as well as adults were waiting for bookshops to open at midnight (Brown 2002: 12). On that same day, The Goblet of Fire took first place on virtually every bestseller list in the US and Britain (Fitzsimmons 2012: 78). Success breeds success in the world of the bestseller: when the final book of the series, Harry Potter and the Deathly Hallows, was published on 7 July 2007, it sold a record 8.3 million copies in the first twenty-four hours in the US alone (Fitzsimmons 2012: 79). It was by then evident that Rowling had created a phenomenon.

The Potter phenomenon is an umbrella term comprising the series' amazing literary, commercial and popular impact. The eight film adaptations, the video games, the theme park attractions, museum exhibits, and the many sorts of merchandise have combined to make the Potter brand a commercial phenomenon; "an economic success in excess of $\$ 15$ billion, making it a touchstone for the world of children's print culture" (Tilley 2013: 93). Literary critics have sometimes preferred to view Harry Potter as a marketing success rather than as a literary achievement. For example, Jack Zipes situates the series in the overall context of the role of "institutional corporate conglomerates" that today control the market of children's literature and whose primary interest, as he claims, is commercial rather than "nurturing good quality books," and John Pennington states that the Potter books are about "monetary success, primarily" (qtd. in Nel 2005: 237). Philip Nel opposes this view, defending Rowling by stating that she has resisted the aggressive marketing methods of Scholastic, Warner Brothers, and Mattel, and that she "deserves credit for her attempts to control a marketing apparatus perpetuated by the American legal system," arguing instead that the series constitute "considerable literary achievements" (2005: 237, 241). Judgements of literary value often hinge on matters of personal taste and as such can hardly be ascertained objectively. What can be asserted with justification is that Rowling's Harry Potter caused a significant change in the world of children's books, and in the domain of the bestseller, when due to the books' bestselling success, The New York Times decided in 2007 to introduce Children's Books as a new bestseller category. This decision was motivated by the fear that The Goblet of Fire would occupy the first place on the bestseller list for too long, and that the various 
Potter books would clog the list; it was necessary to make room "on the adult list for adult titles" according to editor Chip McGrath (Bolonik 2000). Protests came from librarians and scholars of children's literature, who deemed the decision detrimental to the visibility of children's literature. Others saw it as a positive development that would allow children's books their own place, worthy of special attention (Fitzsimmons 2012). It is however undeniable that at that moment, as Fitzsimmons comments, "the series redefined publishing and children's book marketing" (2012: 79).

\section{The bestseller debates}

To explore Rowling's bestsellers it is necessary to first outline the field in which their success is to be understood, a field that has a surprising number of thorny issues. Even the term 'bestseller' itself is a matter of debate. Clive Bloom defines it as "the work of fiction sold in the most units (books in a given price range) to the most people over a set period of time" but also admits that this definition is unclear: it does not specify the understanding of units or fiction itself, nor is there a fixed price or period of time (2008: 28). While it seems evident that a place on a reputable bestseller list confers bestseller status, John Sutherland notes the contradictory nature of proclaiming several "best" titles; since best is a superlative, "better sellers" would be the more correct term, and more appropriate would be "fast-seller," because pace of sale is what defines the category (2007: 18). Others, too, have argued for a refinement into fast-sellers, steady-sellers (which do not sell rapidly but retain popularity) and bestsellers, which sell fast and maintain popularity. Malcolm Cowley suggests a further possible refinement between "a classic (a book admired by intelligent readers through several generations) and a bestseller (a book purchased by many readers in one generation)," though adding that the terms are not mutually exclusive (qtd. in Fitzsimmons 2012: 93). As in fact none of the terms are mutually exclusive, it seems practical to employ the word as it is most commonly used: comprising both the fast-seller and the steady-seller, and harbouring the potential of becoming a classic in time. This is not to say that many years must pass for a book to become a classic. It seems already quite safe to apply the term to Rowling's Harry Potter series, as well as, for example, to Philip Pullman's His Dark Materials fantasy trilogy (which was published between 1995 and 2000).

Inevitably, the rankings of bestseller lists and their reliability are a matter of debate. The New York Times, highly regarded for its bestseller lists, and which at present has no less than twenty-one lists (distinguishing, for instance, between children's middle grade and young adult, graphic novels and manga, print and e-books), acknowledges this debate by providing on its website a detailed justification of its choice of vendors and sales venues, its system of rankings, and its confidentiality policy. In addition, it provides a link to an article explaining the difference between trade books and mass-market books; this essay carefully 
avoids matters of literary taste and instead focuses on measurable facts, such as book sizes, and their placement in shops.

In the bestseller debates, the thorniest issue by far is the matter of the bestseller's literary value. Widespread popularity is frequently considered a marker of inferior literary quality; "books that are popular and books that are good are often two mutually exclusive categories" (Fitzsimmons 2012: 100). That this view has a long history is evidenced by a definition of the bestseller dating from 1934 as "a lively story, largely romantic in theme and setting with conventional characters and plot and some pretention to a message or thesis, apparently profound but really commonplace" (Harvey 1953: 92). According to Miller, the term bestseller is associated with "the mindlessness and conformity" of modern mass society and its taste for the "glib and sensational" (2000: 287). From this standpoint, bestseller lists are critiqued as undermining the educational influence of literary book reviews. Others, and these may be the majority of book buyers, choose to be led by bestseller lists, assuming that if many "have found a book worthy, it must be for a good reason" (Miller 2000: 288). Critiquing Harry Potter, Harold Bloom refutes precisely this view: "Can more than 35 million book buyers, and their offspring, be wrong? Yes, they have been, and will continue to be for as long as they persevere with Potter" (qtd. in Fitzsimmons 2012: 100). While it may be the phenomenal success of the Potter series that has attracted negative appraisals of its literary qualities from many sides, as Fitzsimmons suggests (2012: 100), the view that bestsellers are by definition devoid of literary value is evidently untenable, taking into account that many bestsellers achieved that status after winning prestigious literary prizes. The Man Booker Prize's mission, for instance, is "to increase the reading of quality fiction" as well as "the promotion of genuine artistic talent" (qtd. in Bloom 2008: 3). It would need no argument that the mere fact that Harry Potter is a bestselling series does not suffice to brand it as inferior reading. The question of its merits has been addressed internationally by critics, reviewers and librarians, and first and foremost by reviewers of notable newspapers and journals, and it is part of the broader question of what intrinsic features brought Rowling's first Potter books bestseller success, completely unaided by marketing or publicity strategies.

\section{Is there a success formula?}

What makes a bestseller? This is the enigma that many have attempted to answer since the start of the bestseller lists. One of the earliest attempts is reported in Frank Parker Stockbridge's "What Are the Popular Novels—And Why?" (1931). Concluding his analysis of a selection of bestsellers, Stockbridge states that to generalise is hardly possible: "about the only element those writers have in common is their ability to tell a good story interestingly" (1931: 447). A similar outcome is reported by John Harvey (1953). His analysis of random selections from bestselling novels results in a list of sixteen "content characteristics of the bestseller," most important 
of which are a book's central male character, characters' emotions, and style and theme. These characteristics, combined in a variety of ways, may predict bestseller success. Harvey's conclusion, however, is that the "causal factors behind the sale of best sellers are sufficiently complex and are imbedded so deeply in the psychological and sociological aspects of modern culture that their description cannot be attempted" (1953: 114). Harvey, moreover, points out similar outcomes of studies by Granville Hicks, who analysed forty bestsellers published in the period 1930-1934, and by Edward Weeks, who analysed the 1936 bestselling Gone with the Wind (1953: 114). All three scholars, then, find that a conclusive list of success factors cannot be given. While this seems the most sensible conclusion to the question of what makes a bestseller, the appeal of the quest to find the ingredients of the bestseller recipe remains strong. As James W. Hall remarks about his own motivation in undertaking this research,

when millions of readers, whether they are formally educated or not, have expressed their separate opinions by buying and delighting in a particular novel, there is some larger wisdom at work. Thus, it seemed self-evident to ask one simple question: What is it about this or that enormously popular book that inspires such widespread fervor and devotion? (2012: xv)

From twelve diverse American bestsellers ranging from Margaret Mitchell's Gone with the Wind (1936), and Harper Lee's To Kill a Mockingbird (1960), to Dan Brown's The Da Vinci Code (2003), Hall distils the features that make a bestseller; features so similar, he claims, that they almost appear to have a common ancestor, regardless of the great variety in settings, characters and plots, and the decade in which the books are written (2012: xvii). Nevertheless, Hall states, bestseller success is not guaranteed by the inclusion of the features as such, but by "the unique ways [they] intermingle and resonate" (2012: xvii). In fact, we may add, it seems highly probable that a combination of Hall's features may be found in books that did not achieve bestselling status. Predictions of success cannot be made; indeed, as Potter's publication history shows (and that of many others, including Anne Frank's Diary) even astounding bestseller success often goes initially unrecognised by experienced readers employed by publishing houses. By the same token, writers who imitate a bestselling author's success formula to win some (or much) of that bestseller's celebrity and financial gain do not usually achieve bestselling status themselves.

As a recent publication in the field, Hall's book is of interest to our discussion, and his findings of 'bestselling features' will be used as a context to our findings from the reviews of Rowling's work that appeared in quality papers and journals. A discussion of the first three books that created a worldwide phenomenon is all the more interesting since it was due to their text-internal features that they achieved bestselling success, and ensured widespread popular interest, and indeed bestseller success, for the subsequent instalments. "There is a magic beyond the marketing," Nel states, adding that this is "the magic of good storytelling," as is confirmed by 
"most of the literary criticism to date" (2005: 262). We suggest that there is a good deal of this magic in the early Potter books which rose to fame unaided by marketing, and, possibly, in The Cuckoo's Calling, the novel that obtained favourable reviews unaided by Rowling's reputation. We may also assume that the reviewers of reputable magazines and literary supplements judge books not by their author's fame, but on their own merit, although indisputably, knowledge of the author's previous work is part of the repertoire that is expected of reviewers. The reviews read for this survey are from quality print media; these reviews are not meant to boost sales but constitute the informed opinions of professional readers with expert knowledge of fiction, who are able to evoke and evaluate the works they review fairly and reasonably. As reviews are significant tastemakers in the cultural domain, they will lead our discussion of the success factors in J.K. Rowling's works. ${ }^{2}$

\section{The magic of Harry Potter}

What emerges from the reception of the Potter books as their most remarkable (or, remarked on) feature is Rowling's originality: her creativity and inventiveness. Combining the realism of the boarding school genre with fantasy, and fusing the ordinary world of teenagers and the surreal universe of cosmic evil, Rowling's fictional world is deemed outstanding and original. This inventiveness of form, which also extends to characterisation, setting and atmosphere, is praised so often and emphatically by reviewers that it is clearly the main feature of Harry Potter's success. Already in what is regarded as the first (anonymous) review, published in The Scotsman, Rowling is applauded for her capacity to use "classic narrative devices with flair and originality" (Eccleshare 2002: 10). Praise for Rowling's playful mixing of the mundane and the magical, expressed in various ways throughout the ten years of the Potter releases, indubitably represents the majority view. In her review of the last instalment, The New York Times' critic Michiko Kakutani evaluates the entire series as "[being] deeply rooted in traditional literature and Hollywood sagas ... [fusing] a plethora of genres ... into a story that could be Exhibit A in a Joseph Campbell survey of mythic archetypes" (2007).

Rowling's unique achievement in the Potter series, we may conclude from the reviews, is to create an amazing hybrid world of the mundane and the marvellous, of realism and fantasy intertwined, which offers readers the pleasant thrill of the new as well as the equally pleasant recognition of the familiar. Rowling's major achievement is to have created a fully imagined and original fictional world, "a world so minutely imagined in terms of its history and rituals and rules that it qualifies as an alternate universe" (Kakutani 2007). Various reviewers have made comparisons with other outstanding fictional worlds. For example, Gleick finds Rowling's world "every bit as fantabulous and vividly original as those created by C. S. Lewis, Roald Dahl or, for that matter, George Lucas" (1999); and Hand argues that in masterfully combining meticulous realism and fantasy, Rowling creates a magical world, and "trumps even Tolkien in the sheer humanity of her characters" (2007). ${ }^{3}$ 
Hall's study of bestseller features supports the notion that inventiveness in the use of various combined genres is a major success factor. Hall states that the primary feature of the bestseller is that it has a "dramatic question" (along the lines of "how will our hero manage to survive?") and that this question is enhanced by the "unique and creative mash-ups of traditional genres" (2012: 7). Support of the view that creative mixing of genres and motifs is a prime feature of bestsellers is provided by Kerstin Bergman's article "Genre-Hybridization - a Key to Hyper-Bestsellers?" which argues that hyper-bestsellers are often genre-hybrids, "mixing several different, often popular, fiction genres" (2013: 107). Bergman explains this success by stating that the mixing of genres attracts a greater variety of readers: "genre-hybridity is a fundamental . . . feature that contributes to such a novel's success by causing it to attract a larger and more diverse audience, and in so doing makes it stand out from most regular bestsellers" (2013: 107). Indeed it seems reasonable to assume that whereas fantasy fiction requires a special readerly disposition or willingness to suspend disbelief, a hybrid form of fantasy mixed with realism is less demanding, and will appeal to a wider audience.

If a unique and inventive combination of existing genres and motifs is a major factor in bestseller success, this also applies to character portrayal and development. Rowling's reviews mark characterisation in Harry Potter as the second major feature of its successful storytelling, highlighting Rowling's ability to create a hero who is a rounded and dynamic character, likeable and relatable, yet also 'special' and 'chosen,' with helpers who share these characteristics. Taken together, these characters will evoke strong emotional responses, and will enable identification among readers of different genders, nationalities, ages, or even generations, as many reviews of Harry Potter note. Undoubtedly, then, much of the magic of storytelling in Harry Potter resides in its characterisation, which elicits intense readerly engagement; reviewers are in agreement that Rowling's characters draw us into the story and keep us engaged. Michael Winerip's review of the first Potter book finds that its "real magic" is due to the balancing of emotionality that Rowling achieves, and which enables close readerly involvement: "[she] has a gift for keeping the emotions, fears and triumphs of her characters on a human scale, even while the supernatural is popping out all over"; "We feel Harry's fear," concluding that these emotions make the characters "impressively threedimensional (occasionally four-dimensional!)" (1999). These comments capture the gist of many later reviews; Kakutani finds Harry "an identifiable hero," returning to this point in her review of The Casual Vacancy only to deplore the later book's less successful characterisation (2012).

If, as Hall claims, the "primal aim" of bestsellers is "to stir a reader's heart and to make us forge a powerful emotional bond with a fictional character" (2012: 17), Rowling has achieved that aim optimally, according to her reviewers. Hall specifies that the main attributes of the bestseller's protagonist character are acting decisively and with an "intense commitment" to a cause that "is ultimately a goal most of us find worthy and important"-attributes that will unfailingly evoke an empathetic readerly response (2012: 16). Harry Potter indubitably dis- 
plays this intense commitment throughout the series, eventually risking his own life in the final battle against Voldemort. Further hero characteristics that Hall defines as success factors are also integral to Harry Potter's characterisation: the outsider condition, the fractured family background, and the specialness of this otherwise ordinary person (2012: 156). While all these describe Harry Potter, the primary success factor of Rowling's characterisation may be the combination of the ordinary and the extraordinary in Harry's character. In their article reporting on young readers' responses, Beach and Willner attribute Rowling's success to the main characters being "likable and self-effacing"; Potter and his friends have "fully rounded personalities that are unique yet universal enough to transcend the boundaries of fantasy"; they are fictional characters but also "our friends and family members personified" (2002: 105). In sum, then, we may state that the creative mix of magic and realism that underlies the entire series is a major factor contributing to its successful characterisation, and that this hybridity allows a strong readerly involvement, as a primary feature of bestselling success.

Another, only slightly less important success factor is the long plot and character development that is enabled by the seven-books sequence. This 'series effect' is frequently mentioned by reviewers. Lev Grossman praises Rowling's development of the characters of Harry and Dumbledore, stating that "Rowling has been careful to build Harry up from boy to man, student to leader, but she has been equally attentive to the task of breaking Dumbledore down, from a divine fatherfigure to a mere human" (2007). Others make similar observations, all concluding that the prolonged narrative arc of the series has given ample scope to Rowling's skilful portrayal of the maturation processes of the series' cast. ${ }^{4}$ In this respect, the Potter phenomenon (the series as an outstanding commercial and literary production) has had an effect on children's literature and its marketing. Since 2008, series books have been a significant force in juvenile publishing; as Tilley observes, "publishers now seek out stories ... that can sustain serialization and show promise of franchise and branding success" (2013: 93).

Inventiveness and originality, evidenced through hybridity of form and the creation of a fully imagined world with rounded and dynamic characters, then, are most frequently commented on as Rowling's success factors in reviews, and accord with Hall's findings and other critical responses. While some reviewers also note features such as playfulness, wisdom and humour, these comments are not frequent enough to deserve special mention as bestseller-success features. A feature that would deserve special notice, although it is not mentioned as frequently and consistently as the ones discussed so far, is the series' social commentary. Its engagement with the theme of racial otherness (the 'pure-blood' wizards as opposed to half-breeds or 'mudbloods') is mentioned as a significant element in various reviews. Hall's findings confirm that this feature is a factor contributing to bestseller success, as "an issue that is rooted in some larger national clash that has existed for a long time" (2012: 222). Hall explains this by stating that such an issue may draw readers into the story due to the fact that its focus is not limited by characters' conflicts with themselves, but encompasses larger and more sig- 
nificant forces (2012: 222). This justifies the conclusion that the success of Rowling's Potter series resides not only in her inventiveness and originality in creating a fully imagined, new and enticing fictional universe, but also in her taking on the deep-seated and cross-cultural theme of racism. Rowling's next book, painted on a smaller canvas, nevertheless also engages with social conflict, but it is questionable whether this theme contributed to its bestseller success.

\section{The success of Harry Potter's successors}

What can be objectively stated is that Rowling's first post-Potter novel has none of the genre hybridity nor does it have the "series effect" of Harry Potter, thus lacking what we have determined as the prime success factors. The book was, however, a resounding success. At over a million pre-orders, The Casual Vacancy was already a fast-seller before its publication. Within hours of its release, it reached the first position on the Amazon book list in the US, becoming the second biggest bestseller in the UK since Harry Potter and the Deathly Hallows, which holds the record of the fastest-selling book in history (Farr 2012). While incontestably it is Rowling's fame as a writer that made The Casual Vacancy such a remarkable bestseller, the brand-name effect in itself does not guarantee positive reviews. In fact, Harry Potter often functioned as a yardstick against which this next, much less imaginative, novel failed to compare. Representative of this is a remark in a review in The Times: "The difficulty, in this fat novel, is the difference between the reader's level of interest in a wholly invented world, such as Harry Potter's, and the world we're stuck with" (2012).

With very few predominantly negative appraisals by reviewers, the overall reception of Vacancy is positive, but features such as originality, creativity or inventiveness were not mentioned in the reviews. ${ }^{5}$ Written for an adult readership, and with a realistic suburban town's local politics as its main theme, Vacancy clearly demonstrates different skills of storytelling than Harry Potter. While the majority of the reviewers reported positively on the novel, specifically praising its characterisation, setting and atmosphere, few felt that it displayed the elements of effective storytelling; thus, in the inevitable comparison with Potter, Vacancy did not do well.

What is deemed The Casual Vacancy's strongest point by reviewers is its characterisation, in particularly the believability, multi-dimensionality and affective power of its characters. Grossman lauds the variety of character types ("villain, victim, fool, lover, ally, traitor") and describes the novel as "a big, ambitious, brilliant, profane, funny, deeply upsetting and magnificently eloquent novel of contemporary England" (2012). Tait finds that the characters keep the reader fully engaged (2012). Other reviewers, however, are less positive, and even though they are a minority, their evaluations also carry conviction. Losowsky evaluates the adult characters of Vacancy as "incredibly ... self aware about their dramatic motivations" to such an extent that they leave no ambiguities and consequently 
lose appeal (2012); Kakutani finds the novel a disappointing, two-dimensional story that lacks emotional depth, and whose characters "neither engage nor transport us" (2012). Ulin also remarks that the character portrayal is two-dimensional, the effect being that "we never feel much is at stake" (2012).

Much like the characterisation, the fictional world of Vacancy elicits many positive comments but also a few notable negative appraisals, and those often derive from a comparison with Harry Potter. Tait comments that Vacancy is a rather sour story that needs more of Harry Potter's warmth and charm (2012); Kakutani describes it as dark and disheartening (2012); Moir finds the setting a "blanket of gloom" that has no charm or whimsy (2012); and Craven remarks that the book lacks "the charm that comes with academic gowns and wands" (2012). Based on the reviews, we may conclude that a major difference between Harry Potter and Vacancy resides in atmosphere, or the 'feel' of their storytelling, and that in this respect, Vacancy lacks the magic of Rowling's superior storytelling in Harry Potter.

Rowling's ability to create a fascinating fictional world is not foregrounded in the Vacancy reviews, but some mention is made of the novel's success at evoking a small-town atmosphere. In this respect, reviewers' responses are mixed. Whilst the world of Pagford, according to Tait, invites immersion (2012), Kakutani criticises Vacancy for having a clichéd and dull real-life world (2012), and Ulin comments drily that "Rowling clearly knows how to create a universe that's compelling, consuming even, but Pagford is no such place" (2012). The Vacancy reviews thus confirm the previous conclusion that much of the power of the storytelling of Potter resides in the creation of a world that has a positive emotional tonality, described by reviews as warmth, charm, hope and humour. Even while taking into consideration the series effect of Potter, and its far longer and hence more substantial impact, this seems a distinct difference.

Without Harry Potter to pave the way, we may speculate, The Casual Vacancy would not have become a fast-selling bestseller, and conceivably might not have made it to the bestseller lists. On the other hand, if judged solely on its own merits, the novel might have been more uniformly positively received, since most negative comments stem from the inevitable comparisons with Potter. Speculation aside, we may conclude that even if the features that constitute the effectiveness of Rowling's storytelling in Harry Potter are largely absent in Vacancy, they nevertheless exerted an unmistakable influence. What is certain is that the reviews exerted no influence on the book's bestseller success, considering the fact that even the pre-publication sales were already excellent. In a very real sense, it was the magic of storytelling that made Vacancy a bestseller: the quality that brought fame to the first Potter books and made them popular successes, and which laid the foundation for what became known as Pottermania and the Potter phenomenon. It is this phenomenon that made Vacancy another outstanding commercial success, and possibly slightly impeded the positive reception of the book.

The influence of the Potter series was completely absent during the initial reception of Rowling's second novel for adults, The Cuckoo's Calling. Released in 
April 2013 as Robert Galbraith's debut detective novel, it was not at first a commercial success. Its meteoric rise to fame took place after mid-July 2013, when J.K. Rowling was revealed as its author; after this, the book instantly took first place on the Amazon bestseller list, and soon after on bestseller lists worldwide. In the three months before Rowling's identity was disclosed, an unremarkable number of 1,500 copies of the printed book had been sold (Farr 2012). Before publication the manuscript had been sent anonymously to publishers and declined by at least one, including Orion Books, before its acceptance by Sphere Books, with whom Rowling had collaborated on The Casual Vacancy as the BBC reports in an article titled "JK Rowling Revealed as Author of the Cuckoo's Calling" (2013).

The Cuckoo's Calling, while under its pseudonym authorship, was neither a fast- nor a bestseller, but the book was positively received, and reviews remained predominantly positive also after its true authorship became known. As a detective novel pur sang, it displays no hybridity of form, nor any merging of realism and fantasy. Nevertheless, in a review by Charles Finch, the novel garners praise for that mysterious quality, the magic of fiction: "The Cuckoo's Calling shows that all great fiction - even if it only concerns our workaday world - has its own kind of magic" (2013). While the implicit reference to Harry Potter is evident, it is interesting to ask what features constitute this novel's kind of magic. It is clearly not the appeal of fantasy, nor is there a "chosen" hero whose mission is to conquer cosmic forces. The reviews of this novel justify the conclusion that it is primarily Rowling's skills at character portrayal that informs the particular "magic" that reviewers like Finch have discerned in the narrative. ${ }^{6}$

Characterisation is the feature highlighted in reviews as most successful in this novel, and may be deemed a prime feature of its "magic" of storytelling. Least successful, according to the reviews, is its strict adherence to genre norms. As a detective novel, it is evaluated as conventional, unimaginative, and even outdated or anachronistic. Creativity and originality, then, in using various genres and motifs, are marked as absent in Calling. It seems as if Rowling, in embarking upon the first book of a trilogy in a detective genre, chose to use a formulaic structure in favour of the mixing of generic forms and motifs that was praised as outstanding in Harry Potter's reception. ${ }^{7}$ Without this factor of genre-hybridity, the everyday, realistic fictional world of Calling is more predictable, more limited and common, and in many respects a less enticing world than Harry Potter's. What stands out in the reviews of Vacancy is Rowling's ability to create engaging characters; this, in sum, remains the strongest factor in Rowling's post-Potter success.

Reviewers' comments on Rowling's characterisation in The Cuckoo's Calling focus mainly on the protagonist Cormoran Strike and his assistant Robin Ellacot. Adjectives used are very positive: "appealing" and "likeable" (Waldman 2013), "well-formed," "complex" and "efficiently drawn" (Kakutani 2013; Kaveney 2013); "fascinating" and "true" (Keller 2013). As a detective, Strike is regarded as a successful creation. While Rowling's ironic tone, her use of humour and her realistic representation of local politics are also mentioned favourably in various 
reviews, no other feature of the book receives as much praise as its characterisation. Moreover, whereas reviews of Rowling's Vacancy reported quite a few negative comments about character portrayal, none are noteworthy here.

While the novel is clearly successful in this respect, only a few critics applaud it for its contribution to the crime novel genre. Lawson is one of the few, finding it "an enjoyable, highly professional crime novel" (2013). Commending the novel for its humour and its "old-fashioned virtues," Kerridge nonetheless finds that "there is room for improvement in terms of construction" (2013). More outspokenly, Geier states that "despite the contemporary milieu and sprinkling of F-words, The Cuckoo's Calling is decidedly old-fashioned" (2013). More negative is Corrigan's view of the novel as "clichéd" and even "anachronistic" (2013).

The detective novel genre has been explored by various scholars to define the genre's ideal reader-writer interaction based on its basic features: the crime plot (clues and solution), and stock characters (detective, helper, murderer, victim). The success of Calling as a detective novel, despite its lack of originality, may be understood against those generic features. We will employ Herbert Resnicow's description of these genre characteristics for a brief exploration of the success of Calling as a conventional detective story. As major plot element, the crime of the detective novel must be a one-time murder; it must be planned, not accidental; committed at the beginning of the story; and its motive should be personal (Resnicow 1994). Rowling's crime, the murder of Lula Landry, meets all these requirements: introduced early in the story, it was carefully planned by John Bristow, Lula's adoptive brother, for purely personal reasons (jealousy and sibling rivalry). The second major element concerns the detective's central characters, which are the detective and an assistant. In Resnicow's definition, these characters should "be capable of making mistakes and wrong decisions, of being outwitted and outmuscled, of having human feelings and problems" (1994). Moreover, the detective should be given the same clues as the reader and detect the murderer not through supernatural powers or coincidence, but by a masterful analysis of these clues. Rowling's detective meets all these requirements: he has a plethora of human problems (recently separated from his partner, he is emotionally and financially unstable; he is a veteran of the war in Afghanistan, and has a permanent leg injury). In complete agreement with the conventions as delineated by Resnicow, Strike's solution to the crime is purely rational and scientific; also, the true state of affairs is apparent upon a re-reading, and the crime's solution does not leave any questions. A final basic element of the detective is the murderer, whose genre requirements stipulate that there must only be one killer, of importance to the plot, who is an amateur, though intelligent and competent, and who should not be pure evil but must want to appear an upright citizen. Rowling's Bristow fits this profile perfectly: from the start, he has a crucial role in the plot in engaging Cormoran's services, and presents an honourable front throughout the narrative (seeking truth and justice); he is an amateur, intelligent and competent, adept at covering up his crime. His love for his mother arguably shows us that he is not entirely evil. 
This brief comparison justifies the conclusion that Rowling's first detective novel is indeed entirely conventional. If today's readers of detective fiction are comparable to Janice Radway's romance readers, whose readerly involvement and reading pleasure depended largely on the extent to which their romance novels followed the conventions of the genre, they will have been satisfied with what some reviewers termed the 'classic' plot of The Cuckoo's Calling. While conventionality may contribute to the success of genre fiction, it is nevertheless antithetical to the creativity that we have defined as intrinsic to the magic of storytelling.

\section{The magic of storytelling}

This essay begs to differ politely with Harvey's conclusion in 1953 that the mechanisms that make a bestseller are "imbedded so deeply in the psychological and sociological aspects of modern culture that their description cannot be attempted" (114). We have attempted that description on the basis of a survey of quality reviews, exploring the evaluations of the reviewers for their reflections on the outstanding characteristics of the bestselling series created by J.K. Rowling. Reflecting contemporary cultural taste, as well as influencing cultural taste, the reviews allow a critical evaluation of what is currently deemed intrinsic to bestseller success. In themselves, reviews do not make a book a bestseller, as we have concluded. Interpreting their findings, and contextualising them with previous research into bestseller features, we have sought to achieve a better understanding of the complexities of the bestseller's success-generating features, and of related issues such as the brand-name effect, and the contested literary status of the bestseller.

What, then, makes a bestseller? The easiest answer is undoubtedly: a previous bestseller by the same author; and secondly, a literary award as prestigious as the Pulitzer Prize or the Man Booker Prize. This leaves unanswered the more interesting question of what first makes a book a bestseller without the aid of brand-name or celebrity success; and, also, what makes a record-breaking bestseller. Those questions we have addressed in the context of Rowling's Harry Potter series. Publicity events or marketing strategies played no part in the series' initial success; the first three instalments became international bestsellers entirely on their own strengths. What can be deduced regarding these strengths from the reviews accords well with the features analysed in bestseller studies: inventiveness and originality in fusing genres, motifs, and character traits, and the creation of a fully imagined world in which a protagonist is a 'chosen' hero with a cosmic mission, yet also an ordinary person. Winerip's description of Harry Potter evokes that hero type: "a terrific person we'd love to have for a best friend" (1999).

The magic of Harry Potter's storytelling, then, resides in Rowling's creative and innovative use of deeply embedded storytelling archetypes and motifs. This signal inventiveness is reinforced by the series effect of readers' deepening involvement over time with maturing characters, and which allows the increase of narrative tension over a long period of time, culminating in the final, long-await- 
ed showdown in which good conquers evil. Reinforced by marketing and the publicity of the brand name effect, Harry Potter's originality of genre hybridity, the warmth and humour of its atmosphere, together with its relatable yet extraordinary main characters, account for much of its popular success. Compared with these aspects, the literary quality of Rowling's style must be regarded as a less significant factor, and consequently it has received little attention in our discussion. The fact that it is not lauded by reviewers justifies the conclusion that the literary style of the Potter series is not outstanding, but it is also evident that this lack of fine writing has not been detrimental to its success.

Concluding from the reviews of Rowling's post-Potter novels, it appears that originality and inventiveness, the prime factors in Potter's bestseller success, are lacking in the adult novels, which, as we would suggest, might not have obtained fast- or bestseller status without the Potter phenomenon. This leaves undisputed that the later works are successful in other respects, particularly in their characterisation and atmosphere. However, reviewers of The Casual Vacancy and The Cuckoo's Calling concur that the novels are not outstanding, inventive or innovative, in contrast to Harry Potter. What is notable from the reviews of The Cuckoo's Calling is that its lack of originality of generic form is often deplored. Indeed, as we have demonstrated, the novel adheres too closely to the conventions of the detective genre to be deemed original or inventive in this respect. First released as a debut in this popular genre, the novel was well received, but under Galbraith's authorship it would not, in all probability, have become a bestseller. The reception of this novel, then, again provides evidence of the primary importance of the brand-name effect on bestseller success.

From our discussion of the reception of Rowling's two adult novels it appears that Rowling's paramount strength as a writer is her ability to create interesting and engaging characters. However, from our overall discussion of Rowling's works of the period 1997-2013 we conclude that this ability in itself does not suffice to account for the magic of her storytelling, which resides first and foremost in the creativity that is demonstrated in the Potter books, in their inventive mix of motifs, themes, character traits and plot elements, which together result in a highly original, artistic creation. This conclusion, we suggest, sheds some light on the time-honoured enigma of the magic of storytelling, or on what Stockbridge described in 1931 as the only feature distinguishing the bestseller from other books, which is a writer's "ability to tell a good story interestingly" (447).

\section{Notes}

The word "magic" is frequently used in relation to Rowling's Harry Potter series, not only due to the magical spells and supernatural phenomena in Harry's world, but also to describe the effectiveness of Rowling's narrative strategies. Reviewers that use the word may have been influenced by the frequency with which "magic" or "magical" is coupled with Rowling's story. Examples of such influences would be the title of the award-winning television miniseries Magic Beyond Words: The J.K. Rowling Story, and David Colbert's popular guidebook 
The Magical Worlds of Harry Potter: A Treasury of Myths, Legends, and Fascinating Facts (2001).

2 Reviews consulted are from The New York Times, The Sunday Book Review, Time, Publishers Weekly, The New Yorker, The Guardian, The Mail on Sunday, The Washington Post, The Scotsman, The National Review, The New Republic and The Michigan Quarterly Review. Due to the scope of this essay, the discussion of reviews throughout our essay is necessarily focused on major points only.

3 Whilst the reviewers are in accord on this matter, other critics find Rowling's world less successful. According to A. S. Byatt, "Rowling creates only secondary secondary worlds" and Harold Bloom deplores the lack of "an authentic imaginative vision" (qtd. in Nel 2005: 249). Philip Nel refutes these statements forcefully, concluding that "Rowling's universe is no less fully imagined than Tolkien's" (2005: 255).

$4 \quad$ It should again be noted that Rowling's characterisation has been negatively critiqued, too, but such criticism was negligible in the reviews consulted for this essay. For a short overview of these negative appraisals see Nel (in particular 2005: 246).

$5 \quad$ Reviews consulted are from The New York Times, The Huffington Post, Time, The Guardian, The Times, The Washington Post, The Daily Mail, The Daily Beast, Los Angeles Times, The Daily Mirror, The Economist, The Telegraph, The Scotsman and The Age.

$6 \quad$ Reviews consulted are from The New York Times, The Guardian, The Huffington Post, The Independent, Slate, NPR, Publishers Weekly, Entertainment Weekly, The London Evening Standard, USA Today, The Telegraph and The Chicago Tribune.

7 The second novel of the series, and also a bestseller, is The Silkworm (2014). Its reception falls outside the scope of this essay.

\section{References}

Beach, Sara Ann and Elizabeth Harden Willner (2002) "The Power of Harry: The Impact of J.K. Rowling's Harry Potter Books on Young Readers". World Literature Today 76 (1), 102-106.

Bergman, Kerstin (2013) “Genre-Hybridization - a Key to Hyper-Bestsellers?” Akademisk Kvarter 7 (12), 106-118.

Bloom, Clive (2008) Bestsellers: Popular Fiction Since 1900. Hampshire: Palgrave Macmillan.

Bolonik, Kera (2000) "A List of Their Own". Salon.com, 16 Aug. 2000. <http://www.salon. com/2000/08/16/bestseller/> 17 Feb. 2014.

Brown, Stephen (2002) "Marketing for Muggles: The Harry Potter Way to Higher Profits". Business Horizon 45 (1), 6-14.

Colbert, David (2001) The Magical Worlds of Harry Potter: A Treasury of Myths, Legends, and Fascinating Fact. Lumina Press.

Corrigan, Maureen (2013) “The Only Surprise In Rowling's 'Cuckoo's Calling' Is Its Author". NPR Books, 18 July 2013. < http://www.npr.org/2013/07/18/202732292/the-only-surprise-inrowlings-cuckoos-calling-is-the-author> 14 March 2015.

Craven, Peter (2012) “The Casual Vacancy". The Age, 7 Oct. 2012. <http://www.theage.com.au/ entertainment/books/the-casual-vacancy-20121006-2763e.html> 21 March 2014.

Dawson, Paul (2013) The Return of the Omniscient Narrator: Authorship and Authority in TwentyFirst Century Fiction. Columbus: Ohio State University Press.

Eccleshare, Julia (2002) "The Publishing of a Phenomenon". Guide to the Harry Potter Novels. London: Continuum, 9-11.

Farr, Emma-Victoria (2012) "JK Rowling: Casual Vacancy Tops Fiction Charts". The Telegraph, 3 Oct. 2012. <http://www.telegraph.co.uk/culture/books/booknews/9584404/JK-Rowling-CasualVacancy-tops-fiction-charts.html> 10 March 2015.

Finch, Charles (2013) “The Cuckoo's Calling”. USA Today, 24 July 2013. <http://www.usatoday. com/story/life/books/2013/07/24/the-cuckoos-calling/2581907/> 20 February 2015. 
Fitzsimmons, Rebekah (2012) “Testing the Tastemakers: Children's Literature, Bestseller Lists, and the 'Harry Potter Effect'". Children's Literature 40, 78-107.

Galbraith, Robert (2013) The Cuckoo's Calling. London: Sphere.

Geier, Thom (2013) “The Cuckoo's Calling”. Entertainment Weekly, 19 July 2013. <http://www. ew.com/article/2013/07/19/cuckoos-calling-book> 10 March 2015.

Gleick, Elizabeth (1999) “The Wizard of Hogwarts”. TIME, 12 April 1999, 61.

Grossman, Lev (2007) "Harry Potter's Last Adventure". TIME, 28 June 2007. <http://content.time. com/time/world/article/0,8599,1645771,00.html> 10 March 2015.

Grossman, Lev (2012) “J.K. Rowling's The Casual Vacancy: We've Read It, Here's What We Think". TIME, 27 Sept. 2012. <http://entertainment.time.com/2012/09/27/j-k-rowlings-the-casual-vacancy-weve-read-it-heres-what-we-thought/> 11 March 2015.

Hall, James W. (2012) Hit Lit: Cracking the Code of Twentieth Century's Biggest Bestsellers. New York: Random House.

Hand, Elizabeth (2007) "Harry's Final Fantasy: Last Time's a Charm". The Washington Post, 22 July 2007. <http://www.washingtonpost.com/wp-dyn/content/article/2007/07/21/ AR2007072101025.html> 11 March 2015.

Harvey, John (1953) "The Content Characteristics of Best-Selling Novels". Public Opinion Quarterly 17(1), 91-114.

"JK Rowling Revealed as Author of The Cuckoo's Calling" (2013). BBC, 14 July 2013. <http:// www.bbc.com/news/entertainment-arts-23304181> 8 March 2015.

Kakutani, Michiko (2007) “An Epic Showdown as Harry Potter is Initiated into Adulthood". The New York Times, 19 July 2007. <www.nytimes.com/2007/07/19/books/19potter.html> 15 February 2015.

Kakutani, Michiko (2012) “Darkness and Death, No Magic to Help: 'The Casual Vacancy’ by J.K. Rowling”. The New York Times, 27 Sept. 2012. <http://www.nytimes.com/2012/09/27/books/ book-review-the-casual-vacancy-by-j-k-rowling.html?_r=0> 11 February 2015.

Kakutani, Michiko (2013) "A Murder is Solved, a Sleuth is Born”. The New York Times, 17 July 2013. <http://www.nytimes.com/2013/07/18/books/in-j-k-rowlings-cuckoos-calling-modeldies-but-why.html?_r=0> 11 February 2015.

Kaveney, Roz (2013) “Book Review: The Cuckoo's Calling, by Robert Galbraith (AKA JK Rowling)". The Independent, 19 July 2013. < http://www.independent.co.uk/arts-entertainment/books/ reviews/book-review-the-cuckoos-calling-by-robert-galbraith-aka-jk-rowling-8720530.html $>9$ February 2015.

Keller, Julia (2013) “Review: 'The Cuckoo's Calling' by Robert Galbraith (J.K. Rowling)”. Chicago Tribune, 9 Aug. 2013. <http://articles.chicagotribune.com/2013-08-09/features/ct-prj0811-jk-rowling-cuckoos-calling-robert-galb-20130809> 8 March 2014.

Kerridge, Jake (2013) "JK Rowling's Crime Novel: The Verdict". The Telegraph, 15 July 2013. $<$ http://www.telegraph.co.uk/culture/books/10179626/JK-Rowlings-crime-novel-the-verdict. html> 18 February 2015.

Lawson, Mark (2013) “The Cuckoo's Calling by Robert Galbraith”. The Guardian, 18 July 2013. $<$ http://www.theguardian.com/books/2013/jul/18/cuckoos-calling-robert-galbraith-jk-rowlingreview $>29$ January 2015.

Losowsky, Andrew (2012) “The Casual Vacancy” Review: JK Rowling's Long-Awaited New Book". The Huffington Post, 27 Sept. 2012. <http:/www.huffingtonpost.com/2012/09/26/thecasual-vacancy-review_n_1917058.html> 1 March 2015.

Miller, Laura J. (2000) "The Best-Seller List as Marketing Tool and Historical Fiction". Book History (3), 286-304.

Moir, Jan (2012) "Where's the Magic in this Tale of Middle-Class Monsters?" Daily Mail, 26 Sept. 2012. <http://www.dailymail.co.uk/news/article-2209165/J-K-Rowlings-The-Casual-Vacancyreview.html> 21 March 2014.

Nel, Philip (2005) "Is There a Text in This Advertising Campaign?: Literature, Marketing, and Harry Potter". The Lion and the Unicorn 29 (2), 236-267. 
Resnicow, Herbert (1994) "Rules for the Classic Whodunit". Writer, 107 (8). <http://connection. ebscohost.com/c/articles/9407131141/rules-classic-whodunit> 18 January 2014.

Rowling, J.K. (1997) Harry Potter and the Philosopher's Stone. London: Bloomsbury.

Rowling, J.K. (1998) Harry Potter and the Chamber of Secrets. London: Bloomsbury.

Rowling, J.K. (2000) Harry Potter and the Goblet of Fire. London: Bloomsbury.

Rowling, J.K. (2007) Harry Potter and the Deathly Hallows. London: Bloomsbury.

Rowling, J.K. (2012) The Casual Vacancy. London: Little, Brown and Company.

Stockbridge, Frank Parker (1931) “What Are the 'Popular' Books - and Why?" The English Journal 20 (6), 441-449.

Sutherland, John (2007) Bestsellers: A Very Short Introduction. Oxford: Oxford University Press.

Tait, Theo (2012) "The Casual Vacancy by JK Rowling - Full Review". The Guardian, 28 Sept. 2012. <http://www.theguardian.com/books/2012/sep/27/jk-rowling-casual-vacancy-review> 20 March 2014.

Tilley, Carol L. (2013) “Children's Print Culture”. In Dafna Lemish (ed.) The International Routledge Handbook of Children, Adolescents and Media, 87-94. <www.routledge.com/books/details/9780415783682/> 07 Feb 2015.

Ulin, David (2012) “'Casual Vacancy’ Fails to Conjure Harry Potter's Magic”. Los Angeles Times, 26 Sept. 2012. <http://articles.latimes.com/2012/sep/26/news/la-jc-jk-rowling-casual-vacancy-20120926> 21 February 2014.

Waldman, Katy (2013) "Private 'I'”. Slate, 16 July 2013. <http://www.slate.com/articles/arts/ books/2013/07/the_cuckoo_s_calling_by_j_k_rowling_or_robert_galbraith_reviewed.html 29 March 2014.

Winerip, Michael (1999) "Harry Potter and the Sorcerer's Stone". The New York Times, 14 Feb. 1999. <https://www.nytimes.com/books/99/02/14/reviews/990214.14childrt.html> 13 March 2015.

IRENE VISSER is a Senior Lecturer in Modern English Literature and Culture at the University of Groningen, the Netherlands. Her areas of concentration are contemporary literature, cultural theory and postcolonial literature and theory. Recent publications include "Entanglements of Trauma: Relationality and Toni Morrison's Home" published in Postcolonial Text 9 (2), 2014; and "Trauma and Power in Postcolonial Literary Studies," in M. Balaev (ed.) Contemporary Approaches in Literary Trauma Theory (Palgrave MacMillan, 2014).

LAURA KAAI holds an MA degree in Literary Studies, obtained in 2014 at the University of Groningen, in the department of English Language \& Culture. She is now working as a freelance editor and contemplating a $\mathrm{PhD}$ trajectory in the area of bestseller fiction.

Address: Dr Irene Visser, Department of English Language and Culture, Faculty of Arts, University of Groningen, Oude Kijk in 't Jatstraat 26, 9712 EK Groningen, The Netherlands. [email: i.visser@rug.nl] 